\title{
A systematic review and meta-analysis of thoracoscopic versus thoracotomy sleeve lobectomy
}

\author{
Yifan Zhong ${ }^{1 \#}$, Yang Wang ${ }^{1 \#}$, Xuefei Hu ${ }^{1 \#}$, Gege Wang ${ }^{2}$, Yunlang She ${ }^{1}$, Jiajun Deng ${ }^{1}$, Lei Zhang ${ }^{1}$, \\ Qiao Peng ${ }^{1}$, Yuming Zhu ${ }^{1}$, Gening Jiang ${ }^{1}$, Minglei Yang ${ }^{1,3}$, Dong Xie ${ }^{1}$, Chang Chen ${ }^{1}$ \\ ${ }^{1}$ Department of Thoracic Surgery, Tongji University Affiliated Shanghai Pulmonary Hospital, Tongji University School of Medicine, Shanghai, \\ China; ${ }^{2}$ Institute of Clinical Epidemiology and Evidence - based Medicine, Tongji University School of Medicine, Shanghai, China; ${ }^{3}$ Department of \\ Thoracic Surgery, Ningbo No. 2 Hospital, Chinese Academy of Sciences, Ningbo, China \\ Contributions: (I) Conception and design: Y Zhong, Y Wang, X Hu; (II) Administrative support: M Yang, D Xie, C Chen; (III) Provision of study \\ materials or patients: Y Zhu, G Jiang; (IV) Collection and assembly of data: J Deng, L Zhang, Q Peng; (V) Data analysis and interpretation: G Wang, \\ Y She; (VI) Manuscript writing: All authors; (VII) Final approval of manuscript: All authors. \\ "These authors contributed equally to this work. \\ Correspondence to: Chang Chen, MD, PhD. Department of Thoracic Surgery, Tongji University Affiliated Shanghai Pulmonary Hospital, Tongji \\ University School of Medicine, Shanghai 200443, China. Email: chenthoracic@163.com; Dong Xie, MD, PhD. Department of Thoracic Surgery, \\ Tongji University Affiliated Shanghai Pulmonary Hospital, Tongji University School of Medicine, Shanghai 200443, China. Email: kongduxd@163.com; \\ Minglei Yang, MD. Department of Thoracic Surgery, Ningbo No.2 Hospital, Chinese Academy of Sciences, Ningbo 315010 , China. \\ Email: doctoryml@126.com.
}

Background: Operative safety and oncologic adequacy of thoracoscopic sleeve lobectomy remain controversial. As such, the purpose of this meta-analysis was to evaluate evidence comparing thoracoscopy and thoracotomy in sleeve lobectomy for centrally located non-small cell lung cancer (NSCLC).

Methods: Electronic searches of PubMed and Web of Science databases were undertaken from inception to March 2020. Comparative studies about thoracoscopic and thoracotomy sleeve lobectomy, with evaluation for perioperative outcomes and oncological results were identified. The following outcomes were measured in this meta-analysis: operating time, blood loss, numbers of lymph node, postoperative hospital stay, chest drainage time, postoperative complication rate, mortality, overall survival (OS). The standardized difference (SMD), relative risk (RR) and hazard ratio (HR) with 95\% confidence intervals (CI) were pooled using Stata software.

Results: Six studies generating 281 thoracoscopy and 369 thoracotomy cases were finally included. There was no significant difference in intraoperative blood loss, number of resected lymph nodes, chest drainage time, postoperative complication rate and mortality between two groups. However, thoracoscopic sleeve lobectomy was associated with longer operation time (SMD 0.59, 95\% CI: 0.14 to 1.03, P=0.010). And shorter postoperative hospital stays (SMD $-0.24,95 \% \mathrm{CI}$ : -0.51 to $0.03, \mathrm{P}=0.078$ ) were observed in the thoracoscopy group with marginal significance. Furthermore, sleeve lobectomy via thoracoscopy could achieve comparable OS compared to that via thoracotomy (HR 0.69, 95\% CI: 0.38 to $1.00 ; \mathrm{P}<0.001$ ). In addition, there were no evident publication bias in all observational outcomes.

Conclusions: Current evidence suggests that thoracoscopic sleeve lobectomy is a safe and efficient surgical procedure for centrally located NSCLC, with comparable perioperative outcomes and equivalent oncological results compared to thoracotomy sleeve lobectomy.

Keywords: Video-assisted thoracoscopic surgery (VATS); robotic-assisted thoracoscopic surgery (RATS); thoracotomy; sleeve lobectomy; non-small cell lung cancer (NSCLC)

Submitted May 06, 2020. Accepted for publication Aug 28, 2020.

doi: $10.21037 /$ jtd-20-1855

View this article at: http://dx.doi.org/10.21037/jtd-20-1855 


\section{Introduction}

Centrally located non-small-cell lung cancer (NSCLC) is the second common type of lung neoplasms, and curative intent surgery is the preferred therapeutic strategy (1). Initially, pneumonectomy was introduced as the standard surgical procedure for centrally located NSCLC $(2,3)$. However, over the past decades, sleeve lobectomy with more lung parenchyma sparing and without sacrificing the oncologic radicality has been accepted as an alternative to pneumonectomy for centrally located NSCLC $(4,5)$. Its superiority in perioperative outcomes and long-term survival has been confirmed in many researches $(4,5)$.

With the evolution of the minimally invasive technique, thoracoscopic surgery is extensively adopted in various pulmonary procedures (6-8). However, despite the advantages of thoracoscopic surgery in perioperative outcomes including shorter postoperative hospital stays, decreased chest drainage time and reduced postoperative complication rate (9-11), thoracotomy is still the preferred surgical approach in sleeve lobectomy considering the technical difficulty of thoracoscopic sleeve resection.

Since sleeve lobectomy via thoracoscopy was firstly attempted in 2002 (12), several researches reported the successful implementation of this procedure in hand of experienced surgeons (13-16). Recently, a series of comparative studies further identified the feasibility of thoracoscopic sleeve lobectomy for centrally located NSCLC (17-22). However, its operative safety and oncologic efficacy compared to thoracotomy sleeve lobectomy remain controversial. Therefore, the purpose of this meta-analysis was to evaluate evidence comparing thoracoscopy and thoracotomy sleeve lobectomy in the treatment of centrally located NSCLC. We present the following article in accordance with the PRISMA reporting checklist (available at http://dx.doi.org/10.21037/jtd-20-1855).

\section{Methods}

\section{Search strategy}

This study was guided by the PRISMA protocol (23) and the recommendations from the Cochrane Collaboration (24). Computerized searches of PubMed and Web of Science databases were conducted from inception to March 2020. The Mesh terms included: sleeve lobectomy, thoracoscopy, thoracotomy, VATS, robotics, and centrally located lung cancer.

\section{Study selection}

Inclusion criteria were as follows: (I) patients who were diagnosed with centrally located NSCLC and underwent sleeve lobectomy; (II) randomized controlled trials and observational (cohort and case-control) studies comparing sleeve lobectomy via thoracoscopy versus thoracotomy; (III) if two or more researches included the same cohort, only the largest or the most recently published one was included; (IV) studies whose full texts were available and language was English. Literatures meeting the following criteria were excluded: publications with incomplete data, review articles, editorials, comments, letters, case reports, and animal experiments.

The selection of original studies was according to the process of reviewing titles, abstracts, and full texts. Two independent researchers (J Deng, Y Zhong) preliminarily identified the literatures based on the titles and abstracts according to the predefined selection criteria. A consensus was achieved after discussion in case of disagreement. Thereafter, full texts of potentially relevant literatures were reassessed to determine their conformity with the criteria.

\section{Data extraction and quality assessment}

Relevant data of included articles were initially extracted by two independent investigators (J Deng, Y Zhong) and verified by a senior thoracic surgeon with professionalclinical knowledge (C Chen). Retrieved data were input into a Microsoft Excel (Microsoft Corporation, Redmond, WA, USA, 2019) database.

Video-assisted thoracoscopic surgery (VATS) and roboticassisted thoracoscopic surgery (RATS) cases were integrated into the thoracoscopic group for further comparison with the thoracotomy group. The following outcomes were compared between thoracoscopic and thoracotomy groups: operating time, blood loss, numbers of lymph node; postoperative hospital stay, chest drainage time, postoperative complication rate, mortality, overall survival (OS).

A 'star system' based on Newcastle-Ottawa Scale (NOS) was adopted to estimate the quality of included studies, which is widely applied in the evaluation of nonrandomized studies and comprised of 3 dimensions: selection of subjects, comparability of study groups, and the ascertainment of either the exposure or outcome of interest for case-control or cohort studies (25). Studies with 7-9 stars were graded as high quality whereas those with $<7$ stars were defined as low quality. Any disagreement was resolved by a consensus after discussion. 


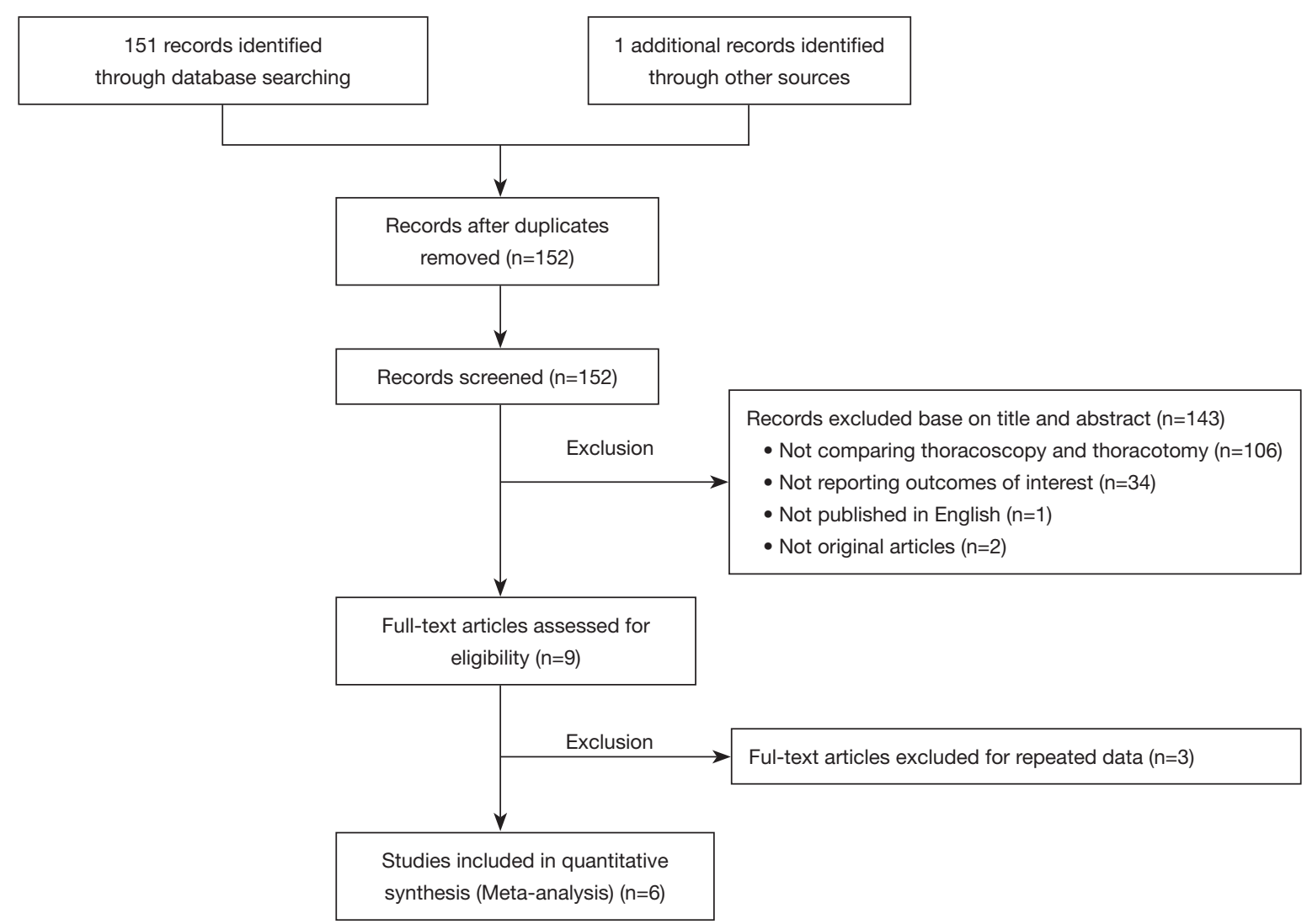

Figure 1 Flow diagram of study selection.

\section{Statistical analysis}

Standardized difference (SMD), relative risk (RR) and hazard ratio (HR) with $95 \%$ confidence intervals (CI) were calculated for continuous and dichotomous variables, respectively. Heterogeneity among different studies was evaluated with utilization of Cochran's Q test and Higgins $\mathrm{I}^{2}$. Statistical heterogeneity was considered as $\mathrm{I}^{2}$ statistic greater than $50 \%$ (26). A fixed-effect model was applied if the heterogeneity was acceptable $(\mathrm{P}>0.10$, or $\mathrm{P} \leq 0.10$ but $\left.\mathrm{I}^{2} \leq 50 \%\right)$. Otherwise, a random effect model was employed. Publication bias were checked by virtue of the funnel plots model and confirmed with Begg's and Egger's tests $(27,28)$. The statistically significant $\mathrm{P}$ value was set at $<0.05$. All mentioned analyses were performed using Stata 14.0 (StataCorp, College Station, TX, USA).

\section{Results}

\section{Study description and quality assessment}

A total of 152 publications were initially discovered from the two aforementioned online databases up to March 2020. After step by step exclusion, 6 cohort studies (17-22) comparing thoracoscopy and thoracotomy sleeve lobectomy were finally included (Figure 1).

The study descriptions and outcomes of the quality assessment were summarized in Table 1 . The study population was comprised of 281 thoracoscopic cases and 369 thoracotomy cases. The mean age of the cohort in every study was more than 60 years old and stage I was the most common pathological stage in the entire population. In addition, all researches were retrospective cohort studies conducted in China and published between 2015 and 2019. Of them, three studies were evaluated as high quality with 7 stars based on NOS.

\section{Baseline characteristics}

As displayed in Table 2, baseline characteristics of patients including age, sex, body mass index (BMI), smoking history, FEV1\%, tumor location, histological type, pathological T stage and pathological $\mathrm{N}$ stage were all similar between the thoracoscopic and thoracotomy groups. 
Table 1 Study description and quality assessment

\begin{tabular}{|c|c|c|c|c|c|c|c|c|c|c|c|}
\hline First author, year & Country & Study type & Treatment & $\begin{array}{c}\text { Conversion } \\
\text { rate }\end{array}$ & $\begin{array}{c}\text { Number of } \\
\text { patients }\end{array}$ & $\begin{array}{l}\text { Mean age, } \\
\text { year }\end{array}$ & $\begin{array}{c}\text { Male vs. } \\
\text { female }\end{array}$ & \multicolumn{3}{|c|}{ Pathological stage } & $\begin{array}{l}\text { Quality } \\
\text { score }\end{array}$ \\
\hline \multirow[t]{2}{*}{ Zhou, 2015} & China & Cohort & Thoracoscopy & $0 \%$ & 10 & 60.5 & $9 / 1$ & 6 & 2 & 2 & 6 \\
\hline & & & Thoracotomy & & 41 & 62.5 & $35 / 6$ & 18 & 10 & 13 & \\
\hline Gu, 2018 & China & Cohort & Thoracoscopy & $1.7 \%$ & 17 & 62.0 & $17 / 0$ & 6 & 5 & 6 & 6 \\
\hline \multirow[t]{2}{*}{ Gao, 2019} & China & Cohort & Thoracoscopy & $5.6 \%$ & 54 & 60.7 & $44 / 10$ & 23 & 19 & 12 & 7 \\
\hline & & & Thoracotomy & & 94 & 60.4 & $87 / 7$ & 20 & 35 & 39 & \\
\hline \multirow[t]{2}{*}{ Qiu, 2019} & China & Cohort & Thoracoscopy & $2.9 \%$ & 122 & 60.4 & $108 / 14$ & $N G$ & $N G$ & $N G$ & 7 \\
\hline & & & Thoracotomy & & 66 & 61.1 & $62 / 4$ & $N G$ & $N G$ & $N G$ & \\
\hline \multirow[t]{2}{*}{ Xie, 2020} & China & Cohort & Thoracoscopy & $4.5 \%$ & 112 & 62.7 & $91 / 21$ & 48 & 35 & 29 & 7 \\
\hline & & & Thoracotomy & & 251 & 62.1 & $234 / 17$ & 104 & 72 & 75 & \\
\hline
\end{tabular}

Quality assessment of included studies was performed using the modified Newcastle-Ottawa Scale (NOS); NG, not given.

\section{Operative time}

Six studies provided information on operative time of sleeve lobectomy, and heterogeneity was identified in these included researches $\left(\mathrm{P}<0.001, \mathrm{I}^{2}=83.3 \%\right)$. The meta-analysis indicated that patients undergoing thoracoscopic sleeve lobectomy experienced significantly longer intraoperative operation time (SMD 0.59, 95\% CI: 0.14, 1.03, P=0.010) (Figure 2).

\section{Blood loss}

Blood loss was evaluated in 6 articles. Compared to thoracotomy, the intraoperative blood loss was similar between thoracoscopic and thoracotomy sleeve lobectomy (SMD $-0.13,95 \% \mathrm{CI}:-0.43$ to $0.18, \mathrm{P}=0.416$ ), with evidence of heterogeneity $\left(\mathrm{P}=0.014, \mathrm{I}^{2}=65.1 \%\right)$ (Figure 3).

\section{Number of resected lymph nodes}

All included researches reported data of number of resected lymph nodes, sleeve lobectomy by thoracoscopic surgery could achieve equivalent performance in intraoperative lymph node resection compared with that by thoracotomy (SMD 0.02, 95\% CI: -0.19 to $0.22, \mathrm{P}=0.878$ ), without evidence of heterogeneity $\left(\mathrm{P}=0.700, \mathrm{I}^{2}=0 \%\right)$ (Figure 4).

\section{Postoperative hospital stay}

In regard to the postoperative hospital stay, the metaanalysis (6 studies estimated this data) revealed shorter postoperative hospital stays in the thoracoscopic sleeve lobectomy with marginal significance (SMD -0.24, 95\% CI: -0.51 to $0.03, \mathrm{P}=0.078)$. Heterogeneity was observed among included studies $\left(\mathrm{P}=0.053, \mathrm{I}^{2}=54.3 \%\right)$ (Figure 5).

\section{Chest drainage time}

Five articles reported data of chest drainage time and our metaanalysis demonstrated that patients receiving sleeve lobectomy via thoracoscopic have similar chest drainage time to those via thoracotomy (SMD $-0.26,95 \% \mathrm{CI}-0.69$ to $0.17, \mathrm{P}=0.235$ ), with specific heterogeneity $\left(\mathrm{P}<0.001, \mathrm{I}^{2}=80.6 \%\right)$ (Figure 6).

\section{Postoperative complication rate}

The type and proportion of complications with the thoracoscopic sleeve and thoracotomy sleeve lobectomy were summarized in Table S1. Of the 6 studies included, the meta-analysis demonstrated that postoperative complication rate estimated by the Forrest plot was similar between two groups (RR 0.74, 95\% CI: 0.51-1.06, $\mathrm{P}=0.103$ ), with no evidence of heterogeneity $\left(\mathrm{P}=0.743, \mathrm{I}^{2}=0 \%\right)$ (Figure 7). 
Table 2 Baseline characteristics between thoracoscopic and thoracotomy sleeve lobectomy

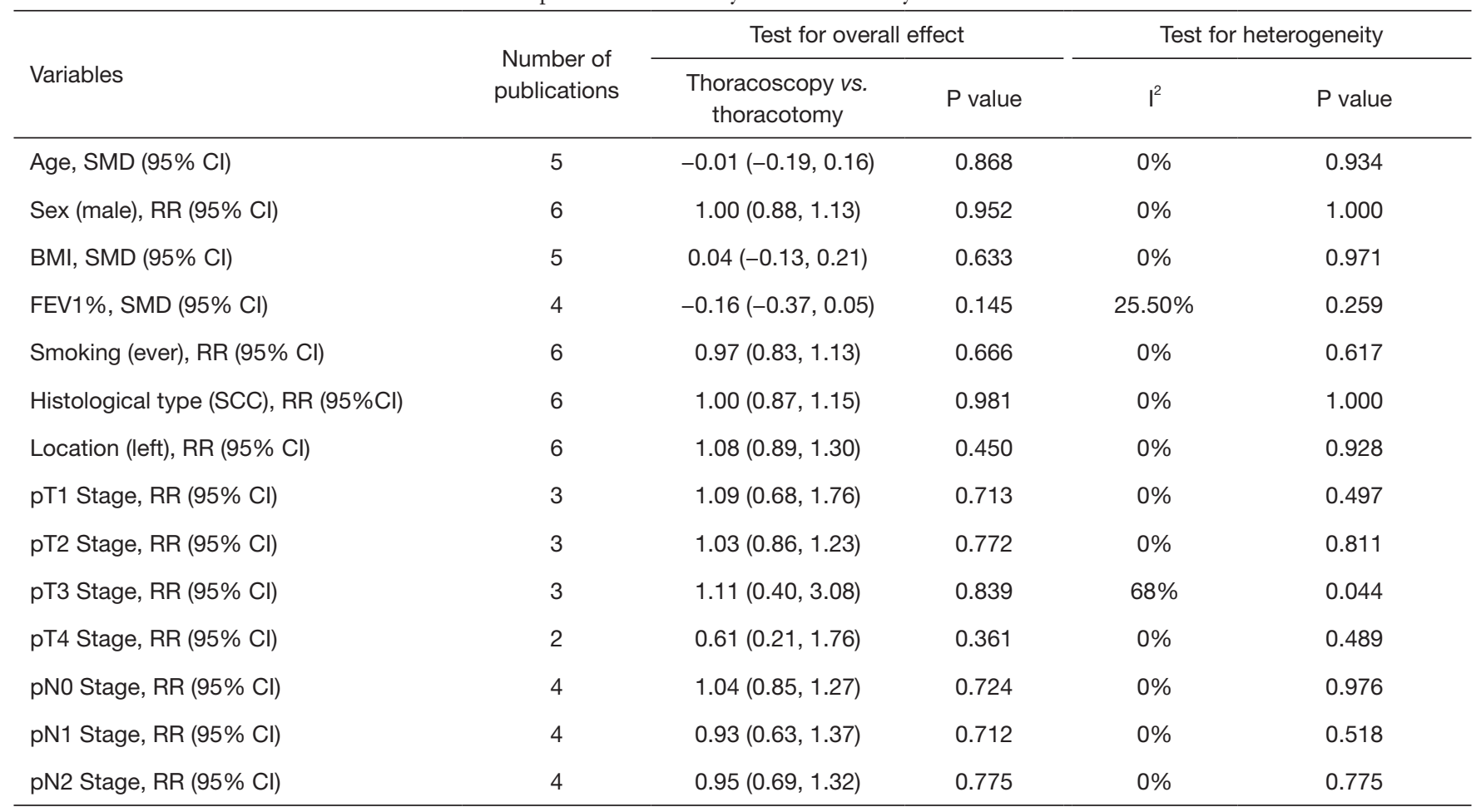

Note: for propensity matched studies, only cases after matching were included. BMI, body mass index; SCC, squamous cell carcinoma.

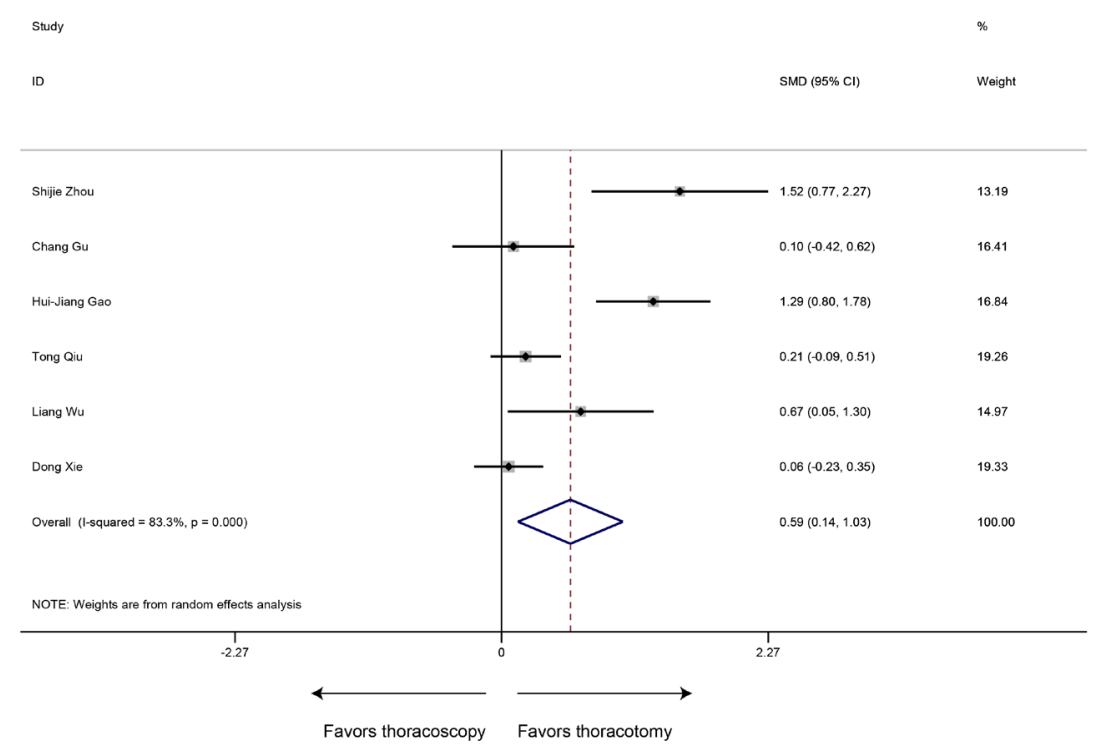

Figure 2 Meta-analysis: the operation time for thoracoscopic and thoracotomy sleeve lobectomy. Note: for propensity matched studies, only cases after matching were included. 


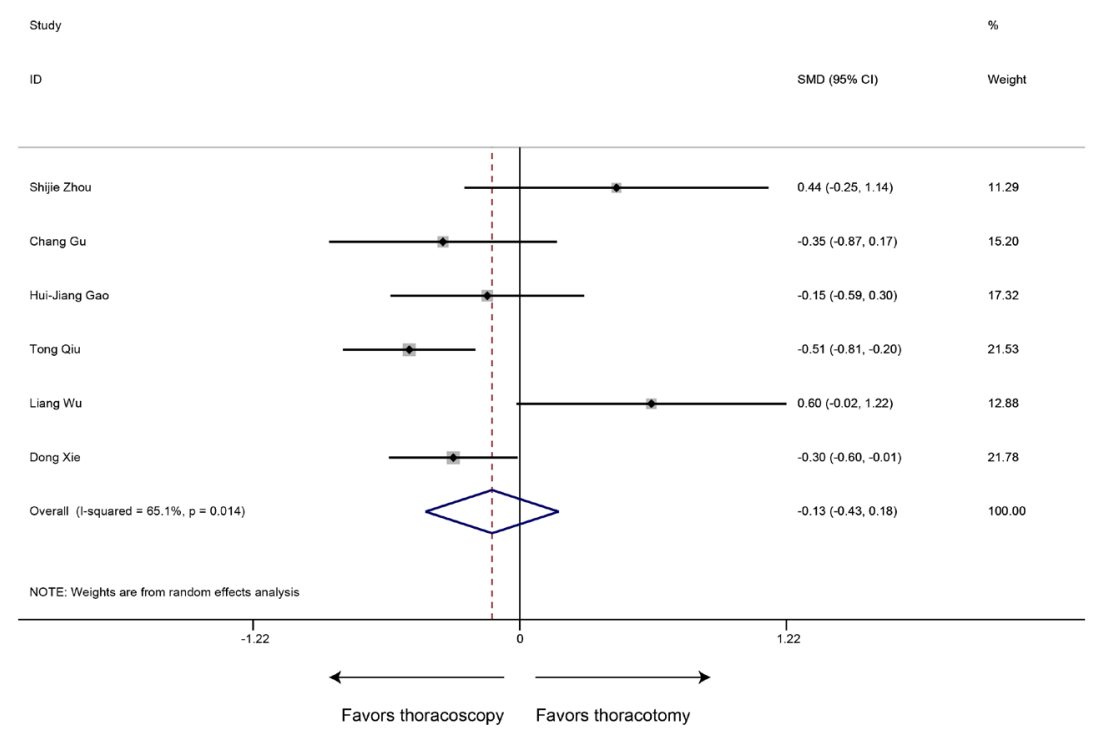

Figure 3 Meta-analysis: the blood loss for thoracoscopic and thoracotomy sleeve lobectomy. Note: for propensity matched studies, only cases after matching were included.

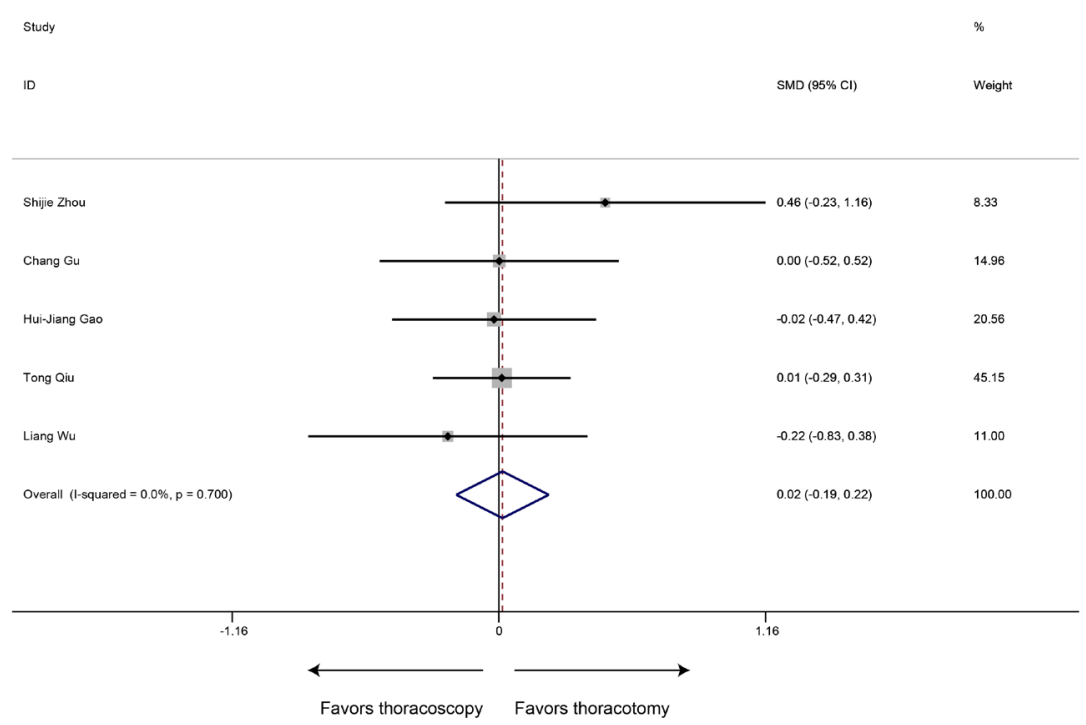

Figure 4 Meta-analysis: the number of resected lymph nodes for thoracoscopic and thoracotomy sleeve lobectomy. Note: for propensity matched studies, only cases after matching were included.

\section{Mortality}

All 6 included publications provided data of mortality, the meta-analysis revealed that thoracoscopic surgery did not increase the mortality of sleeve lobectomy compared to conventional thoracotomy (30-day mortality: RR 0.42, 95\% CI: 0.06-3.12, P=0.394; 90-day mortality: RR 0.55, 95\% CI:
0.15-2.04, $\mathrm{P}=0.367)$ and no significant heterogeneity was identified among publications (30-day mortality: $\mathrm{P}=0.495$, $\mathrm{I}^{2}=0 \%$; 90-day mortality: $\mathrm{P}=0.428, \mathrm{I}^{2}=0 \%$ ) (Figure 8 ).

\section{OS}

OS was defined as the duration from surgery to the date 


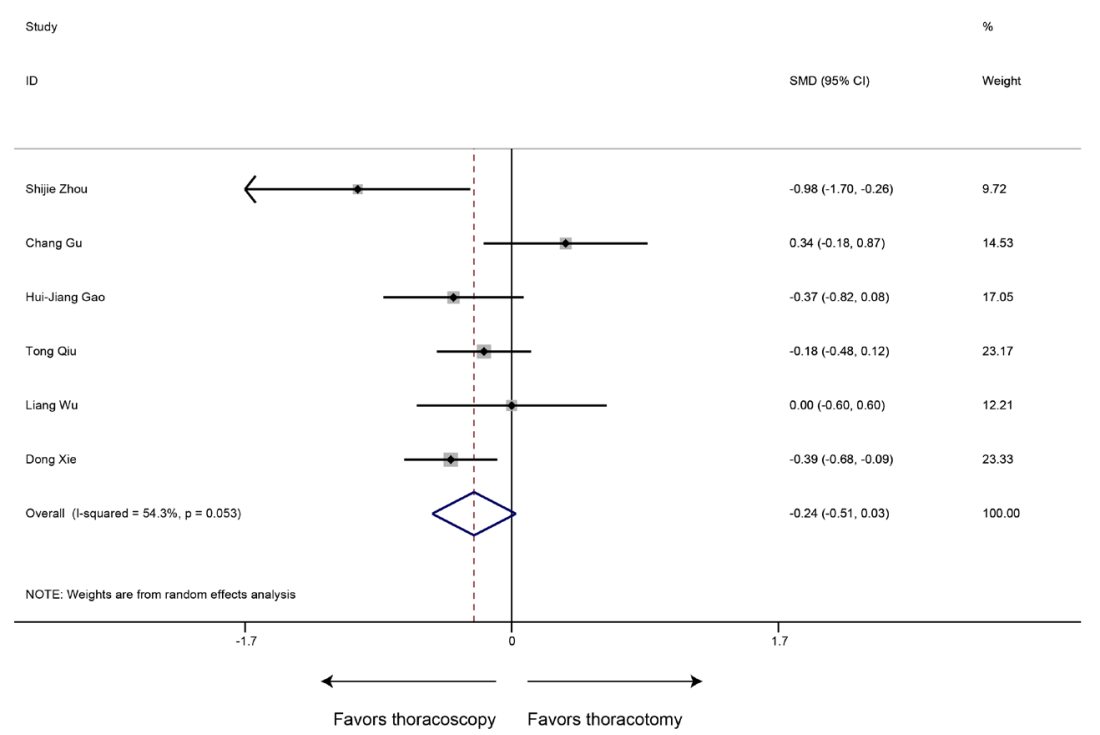

Figure 5 Meta-analysis: the postoperative hospital stay for thoracoscopic and thoracotomy sleeve lobectomy. Note: for propensity matched studies, only cases after matching were included.

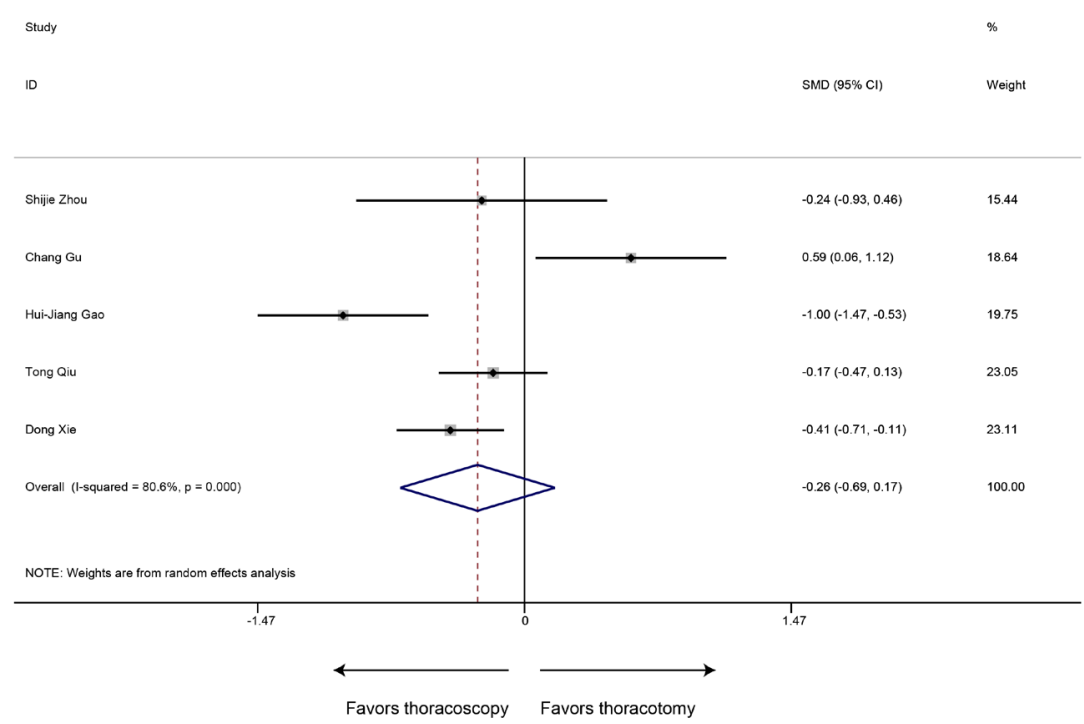

Figure 6 Meta-analysis: the chest drainage time for thoracoscopic and thoracotomy sleeve lobectomy. Note: for propensity matched studies, only cases after matching were included.

of death or last follow-up. 6 studies with 650 patients were included in the analysis of OS. Sleeve lobectomy by thoracoscopy was associated with favorable OS (HR 0.69, 95\% CI: $0.38-1.00 ; \mathrm{P}<0.001)$, without evidence of heterogeneity $\left(\mathrm{P}=0.915, \mathrm{I}^{2}=0 \%\right)$ (Figure 9).

\section{Publication bias}

As displayed in Figure 10, no potential publication bias existed in the HRs of OS among studies according to the asymmetrical distribution of funnel plot, which was further identified by the publication bias test (Begg's test, $\mathrm{P}=0.806$; 


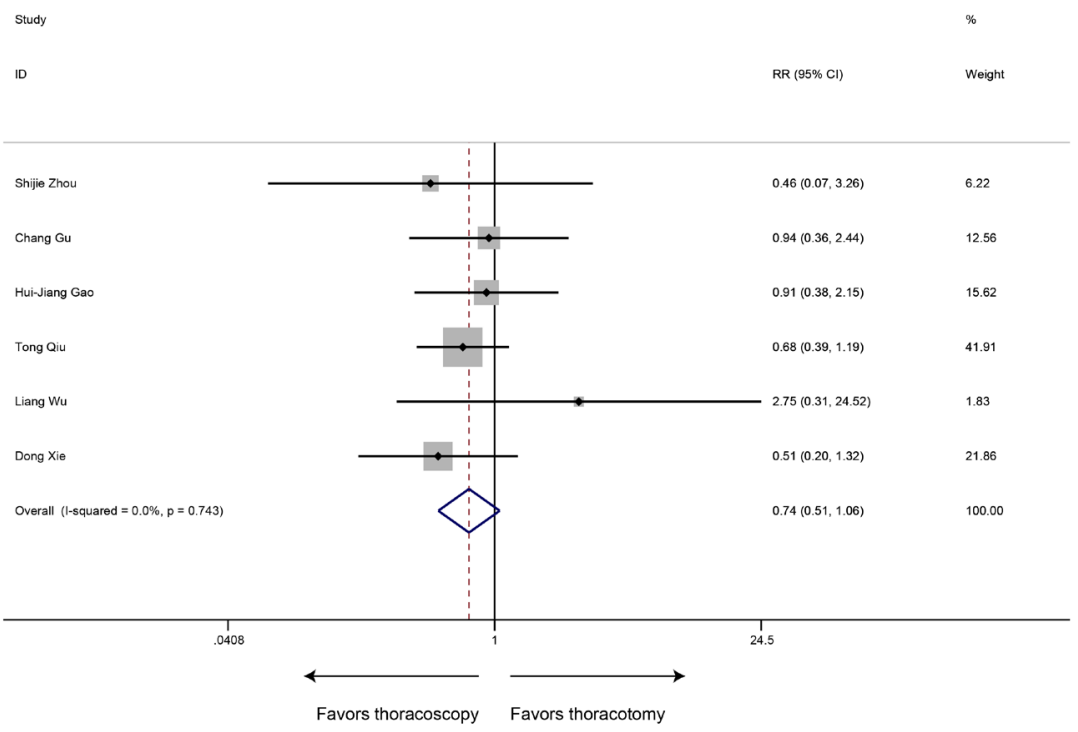

Figure 7 Meta-analysis: the postoperative complication rate for thoracoscopic and thoracotomy sleeve lobectomy. Note: for propensity matched studies, only cases after matching were included.

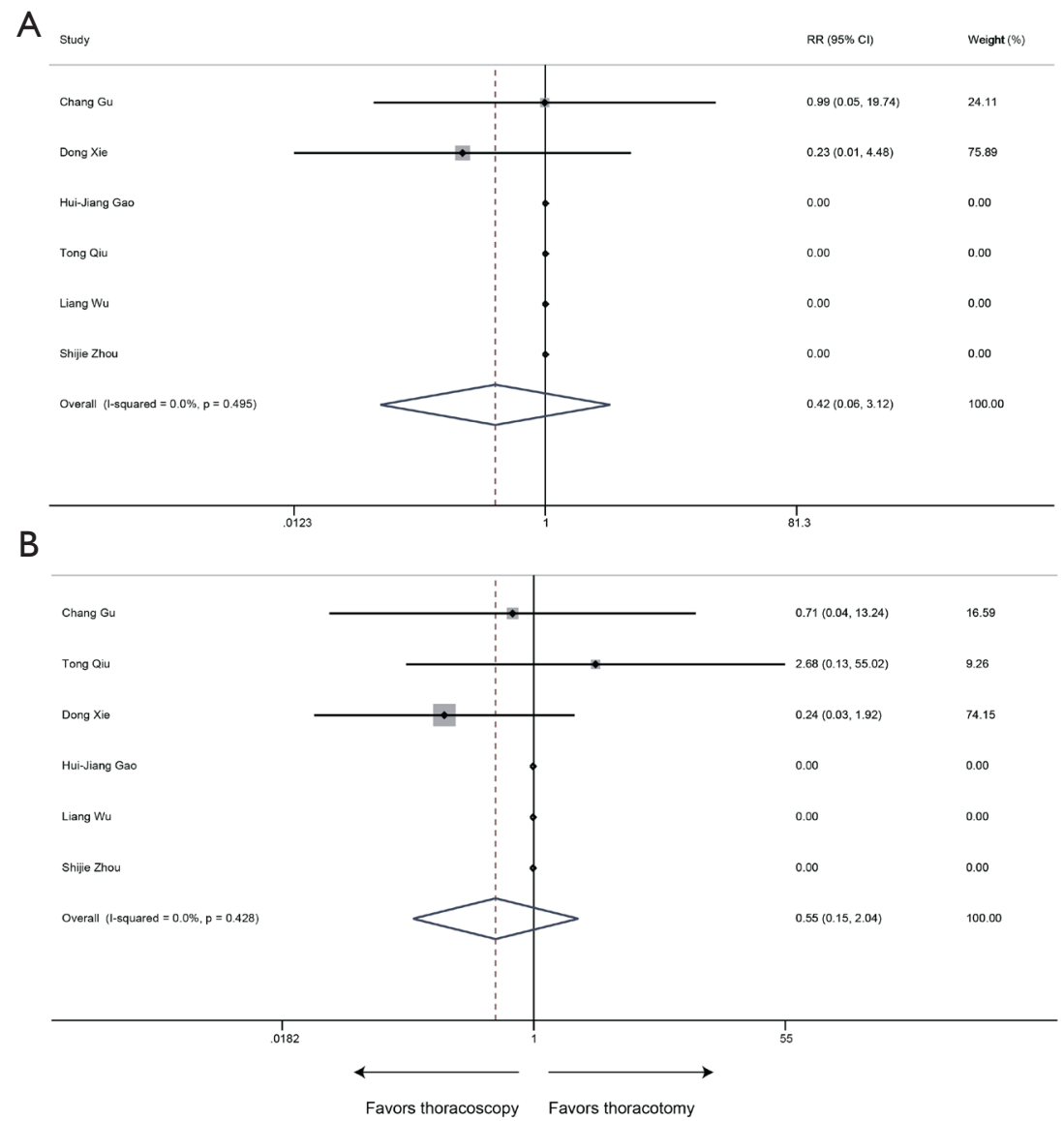

Figure 8 Meta-analysis: the 30-day (A) and 90-day (B) mortality rate for thoracoscopic and thoracotomy sleeve lobectomy. Note: for propensity matched studies, only cases after matching were included. 


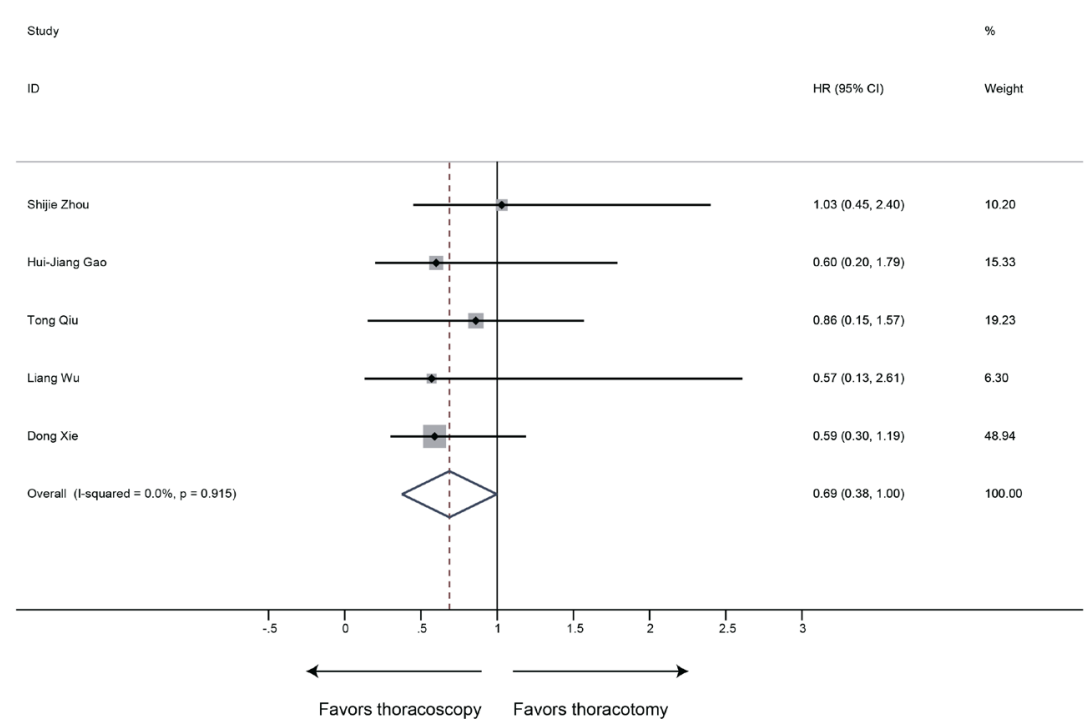

Figure 9 Meta-analysis: the OS for thoracoscopic and thoracotomy sleeve lobectomy. Note: for propensity matched studies, only cases after matching were included.

Egger's test, $\mathrm{P}=0.193)$. Funnel plots of the other results revealed no publication bias (Table S1, Figures S1-S7).

\section{Discussion}

Thoracoscopy has been widely adopted in the surgical management of lung cancer (6-8). Compared to conventional thoracotomy, favorable perioperative outcomes and uncompromising oncologic results could be achieved by this minimally invasive technique (9-11). Sleeve lobectomy, as the standard therapeutic strategy for centrally located NSCLC, was initially regarded as the contradiction for thoracoscopic surgery in consideration of its operative risk $(29,30)$. Since the 21 st century, sleeve lobectomy has been successfully performed via thoracoscopic platform (12-16), but only confined to experienced centers with a small sample size. The feasibility and safety of this procedure have not been fully investigated. Our metaanalysis proved thoracoscopic sleeve lobectomy is a feasible and safe procedure for centrally located NSCLC.

Thoracoscopic sleeve lobectomy has experienced evolution toward less operative trauma over the past decades. In 2002, Santambrogio et al. (12) firstly reported thoracoscopic sleeve bronchoplasty. Subsequently, several series of studies reported their experiences in sleeve lobectomy through video-assisted mini-thoracotomy (30-32). As experience of the thoracoscopic technique accumulated, sleeve lobectomy was successfully performed by complete VATS in 2008 (13). Thereafter, a series of case reports described complete VATS sleeve resection via three and four ports, the operative duration was reported from 176 to 287 minutes and the postoperative hospital stays were between 3 and 8 days (33-35). Over the years, VATS has evolved into a single incision access without rib spreading, which could offer better perioperative outcomes than multi-port surgery (36). In 2013, Gonzalez-Rivas et al. (14) reported the first case of uniportal VATS sleeve lobectomy. The operative time and postoperative hospital stays were 240 minutes and 5 days, respectively. With further advancements in operative technique, surgical equipment and anesthesia management, Shao et al. (16) firstly described complete VATS bronchial sleeve resection under non-intubated epidural anesthesia. In this case, the operative time was 165 minutes, the patient did not require assisted ventilation after surgery, he could drink and eat without any restriction at 4 hours postoperatively and became mobile at the first postoperative day. This patient was discharged after 6 days of operation and no complication was identified.

Nevertheless, thoracotomy was still the preferred surgical approach for sleeve lobectomy considering the high technical demand of sleeve lobectomy and the limitation of VATS in deep perception and maneuverability. The emergence of the RATS has provided the solution for the 


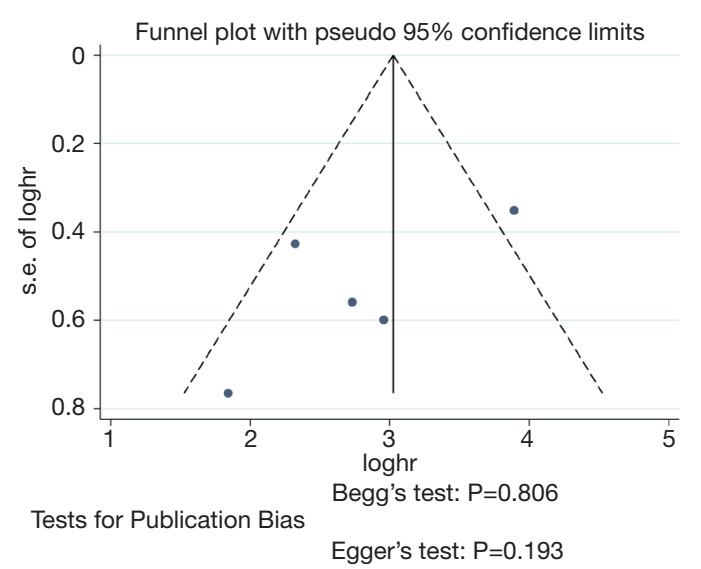

Figure 10 The funnel plot and publication bias tests for the OS of thoracoscopic and thoracotomy sleeve lobectomy. Note: for propensity matched studies, only cases after matching were included.

deficiency of VATS. Schmid et al. (15) initially reported robotic sleeve resection, the operation duration was 364 minutes. And in the following researches, RATS was demonstrated as a safe approach for sleeve lobectomy with satisfactory perioperative outcomes $(37,38)$.

Although the feasibility of thoracoscopic sleeve lobectomy has been proved in many reports, its efficacy compared to thoracotomy sleeve lobectomy remained controversial. Up to now, six studies investigated the operative safety and oncological adequacy of sleeve lobectomy via thoracoscopic surgery by comparing with that by thoracotomy. In these researches, intraoperative performance of thoracoscopic sleeve lobectomy varied in different centers. Four studies demonstrated that the VATS group experienced significantly longer operative duration than the thoracotomy group $(17,19,20,22)$ and Qiu et al. (19) further identified that RATS can offer a significant advantage on operative duration over thoracotomy in bronchial sleeve lobectomy. While, similar operation time between the thoracoscopic and thoracotomy groups was identified in other two studies $(18,21)$. Concerning on intraoperative blood loss, three articles suggested less estimated blood loss in thoracoscopic sleeve lobectomy $(17,19,21)$. But no significant difference between two surgical approaches was observed in the remaining three publications $(18,20,22)$. Discrepancy of operative expertise and impact of learning curve might contribute to the heterogeneity in intraoperative performance among medical centers. In larger and more experienced centers, sleeve lobectomy via thoracoscopic surgery could confer superiority in perioperative outcomes over that by thoracotomy $(21,22)$. Radical lymphadenectomy is of great importance in reducing the late recurrence risk after surgical resection of tumors. For all six included researches, there was no significant difference in performance of intraoperative lymph node dissection between thoracoscopy and thoracotomy groups (17-22).

In terms of postoperative outcomes, five included studies revealed no statistical difference in postoperative complication rate between the thoracoscopic and thoracotomy groups (17-20,22). Only one research proved lower complication rate after thoracoscopic sleeve resection (21). And for all included studies, mortality rate was similar between the thoracoscopic and thoracotomy group (17-22). In addition, postoperative hospital stays and chest drainage time were significantly shorter in patients receiving thoracoscopic sleeve lobectomy, which was proved by most included articles $(17,19,21,22)$. Regarding oncologic results, all six studies demonstrated that thoracoscopic sleeve lobectomy can achieve equivalent OS compared to thoracotomy sleeve lobectomy (17-22). The main reason for the hesitation to perform sleeve lobectomy is the concern about the local recurrence. Unfortunately, the results of local recurrence were only obtainable in two articles $(19,21)$, which limited the implementation of meta-analysis based on this factor, these two studies showed no significant difference in local recurrence rate between thoracoscopic and thoracotomy sleeve lobectomy.

To the best of our knowledge, this is the first study evaluating the efficacy of thoracoscopic sleeve lobectomy by virtue of meta-analysis. In this study, comparable perioperative outcomes and oncologic results were identified in the patients undergoing sleeve lobectomy via thoracoscopic surgery compared to thoracotomy, which confirmed the efficacy of thoracoscopic sleeve lobectomy. The thoracoscopic group experienced longer operation time than the thoracotomy group, which might arise from the operative difficulty of sleeve lobectomy and nonproficiency of the thoracoscopic technique. Proficiency of thoracoscopic sleeve lobectomy varied among different centers, the intraoperative performance was usually better in more experienced centers. Also, there was heterogeneity of experience on thoracoscopic sleeve lobectomy among surgeons, most included studies did not adjust the bias of surgeons, which affected the intraoperative outcomes between thoracoscopic and thoracotomy groups. In general, with the increasing proficiency, thoracoscopic 
surgery could achieve equivalent operative performance to thoracotomy (39-41). Additionally, as displayed in Figure 9, our research revealed thoracoscopic sleeve lobectomy can offer a significant advantage on OS over thoracotomy sleeve lobectomy $(\mathrm{P}<0.001$, HR 0.38-1.00). However, in the original results of all included studies, no significant difference was observed in OS between two groups, which might be the consequence of the limited sample size of thoracoscopic sleeve lobectomy.

Several limitations of this meta-analysis should be acknowledged. Firstly, all included researches were retrospective cohort studies which have certain inevitable bias. We evaluated the quality of publications based on a widely adopted instrument for observational studies and judged most included researches at high quality. Additionally, the funnel plot and bias test of most variables did not indicate evident publication bias among included studies, which was also reassuring. And we hope a randomized controlled trial in future can validate our conclusions.

Secondly, the quantity of included publications in this study was relatively small and every included study was single-center design based on Chinese population. Currently, only experienced medical institutions can routinely perform thoracoscopic sleeve lobectomy in view of the technical difficulty of this surgical procedure. Further, China has the largest population of lung cancer in the world and many centers in China have accumulated adequate experiences in thoracoscopic sleeve lobectomy. Still, a large-scale international study in future is warranted to verify results in our research.

Thirdly, there were limitations in the scope of analysis process. Systematic analyses could not be conducted for variables only described in a small number of researches such as recurrence-free survival and local recurrence. Additionally, limited by the number of studies investigating thoracoscopic sleeve lobectomy, the uniportal VATS, multiportal VATS and RATS cases were analyzed as a whole when compared with the thoracotomy group and subgroup analyses based on surgical approaches could not be performed, so the potential bias resulting from the differences among these three surgical approaches are inevitable. Furthermore, the follow-up time of the survival data in all included studies was relatively short, which weakened the level of evidence for the oncologic efficacy of thoracoscopic sleeve lobectomy.

Finally, significant heterogeneity existed among some variables in our study. Every center adopted specific inclusion and evaluation criteria for postoperative complications, resulting in the difference of complication rate among studies. Moreover, the indication of thoracoscopic sleeve lobectomy and experience for this surgical procedure varied among surgeons, which might contribute to the heterogeneity in intraoperative performance and oncological results. We tried to identify the sources of heterogeneity from original researches, however most articles did not provide relevant information.

\section{Conclusions}

Current evidence suggests that thoracoscopic sleeve lobectomy is a safe and efficient surgical procedure for centrally located NSCLC, with uncompromising perioperative outcomes and equivalent oncological results compared to thoracotomy sleeve lobectomy. This conclusion requires confirmation by more large-scale and high-quality researches.

\section{Acknowledgments}

The authors would like to thank the biostatistician, Prof. Zhang Aihong (Department of Medical Statistics, Tongji University School of Medicine, Shanghai, China), for the design and guidance of statistical analysis in this research.

Funding: This study was supported by Clinical Research Foundation of Shanghai Pulmonary Hospital (FK1943, FK1936, FK1942, FK1941), Shanghai Municipal Health Commission (2018ZHYL0102, 2019SY072), Medicine and Public Health Scientific Projects in Zhejiang Province (2020KY270) and Huamei Key Research Foundation (2019HMZD05).

\section{Footnote}

Reporting Checklist: The authors have completed the PRISMA reporting checklist. Available at http://dx.doi. org/10.21037/jtd-20-1855

Peer Review File: Available at http://dx.doi.org/10.21037/jtd20-1855

Conflicts of Interest: All authors have completed the ICMJE uniform disclosure form (available at http://dx.doi. org/10.21037/jtd-20-1855). The authors have no conflicts of interest to declare. 
Ethical Statement: The authors are accountable for all aspects of the work in ensuring that questions related to the accuracy or integrity of any part of the work are appropriately investigated and resolved.

Open Access Statement: This is an Open Access article distributed in accordance with the Creative Commons Attribution-NonCommercial-NoDerivs 4.0 International License (CC BY-NC-ND 4.0), which permits the noncommercial replication and distribution of the article with the strict proviso that no changes or edits are made and the original work is properly cited (including links to both the formal publication through the relevant DOI and the license). See: https://creativecommons.org/licenses/by-nc-nd/4.0/.

\section{References}

1. Siegel RL, Miller KD, Jemal A. Cancer statistics, 2020. CA Cancer J Clin 2020;70:7-30.

2. Brewer LA 3rd. The first pneumonectomy. Historical notes. J Thorac Cardiovasc Surg 1984;88:810-26.

3. Graham EA, Singer JJ. Landmark article Oct 28, 1933. Successful removal of an entire lung for carcinoma of the bronchus. JAMA 1984;251:257-60.

4. Berry MF, Worni M, Wang X, et al. Sleeve lobectomy for non-small cell lung cancer with $\mathrm{N} 1$ nodal disease does not compromise survival. Ann Thorac Surg 2014;97:230-5.

5. Pages PB, Mordant P, Renaud S, et al. Sleeve lobectomy may provide better outcomes than pneumonectomy for non-small cell lung cancer. A decade in a nationwide study. J Thorac Cardiovasc Surg 2017;153:184-95.e3.

6. Sun HH, Sesti J, Donington JS. Surgical Treatment of Early 1 Stage Lung Cancer: What has Changed and What will Change in the Future. Semin Respir Crit Care Med 2016;37:708-15.

7. Nakazawa S, Shimizu K, Mogi A, et al. VATS segmentectomy: past, present, and future. Gen Thorac Cardiovasc Surg 2018;66:81-90.

8. Menna C, Ibrahim M, Rendina EA, et al. Cost/efficacy evaluation of the technologies applied to video-assisted thoracoscopic surgery lobectomy. J Vis Surg 2017;3:152.

9. Kwon ST, Zhao L, Reddy RM, et al. Evaluation of acute and chronic pain outcomes after robotic, video-assisted thoracoscopic surgery, or open anatomic pulmonary resection. J Thorac Cardiovasc Surg 2017;154:652-9.e1.

10. Yang HX, Woo KM, Sima CS, et al. Long-term Survival Based on the Surgical Approach to Lobectomy For Clinical Stage I Nonsmall Cell Lung Cancer: Comparison of Robotic, Video-assisted Thoracic Surgery, and Thoracotomy Lobectomy. Ann Surg 2017;265:431-7.

11. Bendixen M, Jørgensen OD, Kronborg C, et al. Postoperative pain and quality of life after lobectomy via video-assisted thoracoscopic surgery or anterolateral thoracotomy for early stage lung cancer: a randomised controlled trial. Lancet Oncol 2016;17:836-44.

12. Santambrogio L, Cioffi U, De Simone M, et al. Videoassisted sleeve lobectomy for mucoepidermoid carcinoma of the left lower lobar bronchus: a case report. Chest 2002;121:635-6.

13. Mahtabifard A, Fuller CB, McKenna RJ Jr. Video-assisted thoracic surgery sleeve lobectomy: a case series. Ann Thorac Surg 2008;85:S729-32.

14. Gonzalez-Rivas D, Fernandez R, Fieira E, et al. Uniportal video-assisted thoracoscopic bronchial sleeve lobectomy: first report. J Thorac Cardiovasc Surg 2013;145:1676-7.

15. Schmid T, Augustin F, Kainz G, et al. Hybrid videoassisted thoracic surgery-robotic minimally invasive right upper lobe sleeve lobectomy. Ann Thorac Surg 2011;91:1961-5.

16. Shao W, Phan K, Guo X, et al. Non-intubated complete thoracoscopic bronchial sleeve resection for central lung cancer. J Thorac Dis 2014;6:1485-8.

17. Gao HJ, Jiang ZH, Gong L, et al. Video-assisted Versus Thoracotomy Sleeve Lobectomy for Lung Cancer: a Propensity Matched Analysis. Ann Thorac Surg 2019.

18. Gu C, Pan X, Chen Y, et al. Short-term and mid-term survival in bronchial sleeve resection by robotic system versus thoracotomy for centrally located lung cancer. Eur J Cardiothorac Surg 2018;53:648-55.

19. Qiu T, Zhao Y, Xuan Y, et al. Robotic sleeve lobectomy for centrally located non-small cell lung cancer: a propensity score weighted comparison with thoracoscopic and open surgery. J Thorac Cardiovasc Surg 2020;160:838-46.e2.

20. Wu L, Wang H, Cai H, et al. Comparison of Double Sleeve Lobectomy by Uniportal Video-Assisted Thoracic Surgery (VATS) and Thoracotomy for NSCLC Treatment. Cancer Manag Res 2019;11:10167-74.

21. Xie D, Deng J, Gonzalez-Rivas D, et al. Comparison of Video-assisted Thoracoscopic Surgery with Thoracotomy in Bronchial Sleeve Lobectomy for Centrally Located Non-Small Cell Lung Cancer. J Thorac Cardiovasc Surg 2020. [Epub ahead of print].

22. Zhou S, Pei G, Han Y, et al. Sleeve lobectomy by videoassisted thoracic surgery versus thoracotomy for non-small cell lung cancer. J Cardiothorac Surg 2015;10:116.

23. Moher D, Liberati A, Tetzlaff J, et al. Preferred reporting 
items for systematic reviews and meta-analyses: the PRISMA statement. PLoS Med 2009;6:e1000097.

24. Higgins JPT, Green S (editors). Cochrane handbook for systematic reviews of interventions, 2011. The Cochrane Collaboration. Available online: http://www.cochranehandbook.org

25. Stang A. Critical evaluation of the Newcastle-Ottawa scale for the assessment of the quality of nonrandomized studies in meta-analyses. Eur J Epidemiol 2010;25:603-5.

26. Higgins JP, Thompson SG. Quantifying heterogeneity in a meta-analysis. Stat Med 2002;21:1539-58.

27. Begg CB, Mazumdar M. Operating characteristics of a rank correlation test for publication bias. Biometrics 1994;50:1088-101.

28. Egger M, Davey Smith G, Schneider M, et al. Bias in meta-analysis detected by a simple, graphical test. BMJ 1997;315:629-34.

29. Demmy TL, James TA, Swanson SJ, et al. Troubleshooting video-assisted thoracic surgery lobectomy. Ann Thorac Surg 2005;79:1744-52; discussion 1753.

30. McKenna RJ Jr, Houck W, Fuller CB. Video-assisted thoracic surgery lobectomy: experience with 1,100 cases. Ann Thorac Surg 2006;81:421-5; discussion 425-6.

31. Nakanishi K. Video-assisted thoracic surgery lobectomy with bronchoplasty for lung cancer: initial experience and techniques. Ann Thorac Surg 2007;84:191-5.

32. He J, Yang Y, Chen H, et al. Bronchial sleeve resection and reconstruction of pulmonary artery by video-assisted thoracic small incision surgery for lung cancer. Zhongguo Fei Ai Za Zhi 2007;10:301-5.

Cite this article as: Zhong Y, Wang Y, Hu X, Wang G, She Y, Deng J, Zhang L, Peng Q, Zhu Y, Jiang G, Yang M, Xie D, Chen C. A systematic review and meta-analysis of thoracoscopic versus thoracotomy sleeve lobectomy. J Thorac Dis 2020;12(10):5678-5690. doi: 10.21037/jtd-20-1855
33. Agasthian T. Initial experience with video-assisted thoracoscopic bronchoplasty. Eur J Cardiothorac Surg 2013;44:616-23.

34. Mei J, Pu Q, Liao H, et al. Initial experience of videoassisted thoracic surgery left upper sleeve lobectomy for lung cancer: Case report and literature review. Thorac Cancer 2012;3:348-52.

35. Li Y, Wang J. Video-assisted thoracoscopic surgery sleeve lobectomy with bronchoplasty: an improved operative technique. Eur J Cardiothorac Surg 2013;44:1108-12.

36. Shen Y, Wang H, Feng M, et al. Single- versus multipleport thoracoscopic lobectomy for lung cancer: a propensity-matched study $\dagger$. Eur J Cardiothorac Surg 2016;49 Suppl 1:i48-53.

37. Pan X, Gu C, Wang R, et al. Initial Experience of Robotic Sleeve Resection for Lung Cancer Patients. Ann Thorac Surg 2016;102:1892-7.

38. Cerfolio RJ. Robotic sleeve lobectomy: technical details and early results. J Thorac Dis 2016;8:S223-6.

39. Arnold BN, Thomas DC, Bhatnagar V, et al. Defining the learning curve in robot-assisted thoracoscopic lobectomy. Surgery 2019;165:450-4.

40. Vieira A, Bourdages-Pageau E, Kennedy K, et al. The learning curve on uniportal video-assisted thoracic surgery: An analysis of proficiency. J Thorac Cardiovasc Surg 2020;159:2487-2495.e2.

41. Yao F, Wang J, Yao J, et al. Video-Assisted Thoracic Surgical Lobectomy for Lung Cancer: Description of a Learning Curve. J Laparoendosc Adv Surg Tech A 2017;27:696-703. 
Supplementary

Table S1 The type and proportion of complications with the thoracoscopic sleeve and thoracotomy sleeve lobectomy

\begin{tabular}{|c|c|c|}
\hline \multirow{2}{*}{ Types of complication } & \multicolumn{2}{|c|}{ All included cases $(n=650)$} \\
\hline & Thoracoscopy $(n=281), \%$ & Thoracotomy $(n=369), \%$ \\
\hline Prolonged air leak & 1.83 & 2.72 \\
\hline Cardiac arrhythmia & 2.14 & 2.71 \\
\hline Atelectasis & 1.21 & 1.60 \\
\hline Pneumonia & 4.47 & 5.16 \\
\hline Chylothorax & 1.07 & 2.34 \\
\hline Pulmonary embolus & 0.71 & 0.54 \\
\hline Bronchopleural fistula & 2.06 & 1.63 \\
\hline Subcutaneous emphysema & 1.47 & 1.31 \\
\hline Pyothorax & 0.71 & 0.54 \\
\hline Bronchial anastomosis bleeding & 0.36 & 0 \\
\hline Anastomosis bursting & 0 & 0.27 \\
\hline Multiple organ failure & 0.36 & 0 \\
\hline Recurrent laryngeal nerve injury & 0 & 0.27 \\
\hline Anastomotic stenosis/obstruction & 0.44 & 0.54 \\
\hline Postoperative tracheotomy & 0 & 0.27 \\
\hline Pneumothorax & 1.20 & 0.07 \\
\hline Hemothorax & 0.35 & 0.27 \\
\hline Pleural effusion & 0.59 & 0.93 \\
\hline Acute myocardial infarction & 0.29 & 0 \\
\hline Respiratory failure & 0 & 0.27 \\
\hline
\end{tabular}

For propensity matched studies, only cases after matching were included. 


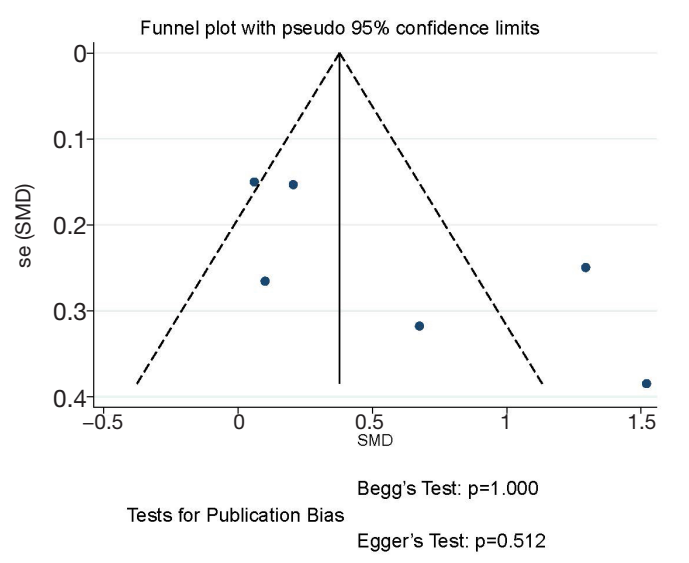

Figure S1 The funnel plot and publication bias tests for operative time of thoracoscopic and thoracotomy sleeve lobectomy. Note: for propensity matched studies, only cases after matching were included.

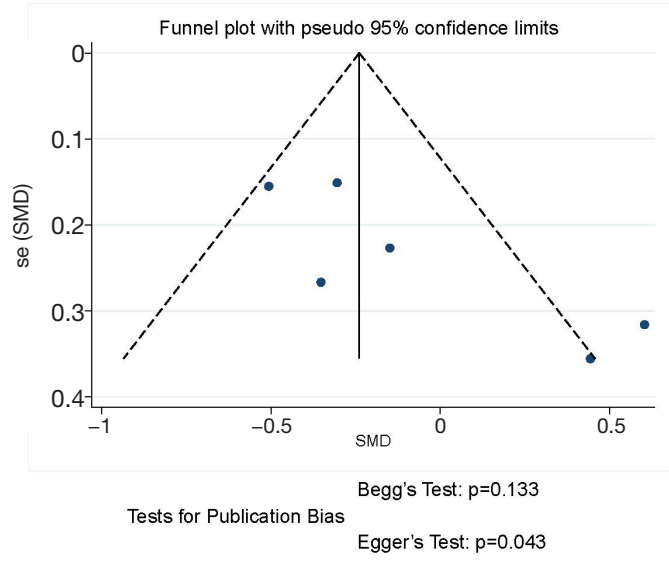

Figure S2 The funnel plot and publication bias tests for blood loss of thoracoscopic and thoracotomy sleeve lobectomy. Note: for propensity matched studies, only cases after matching were included.

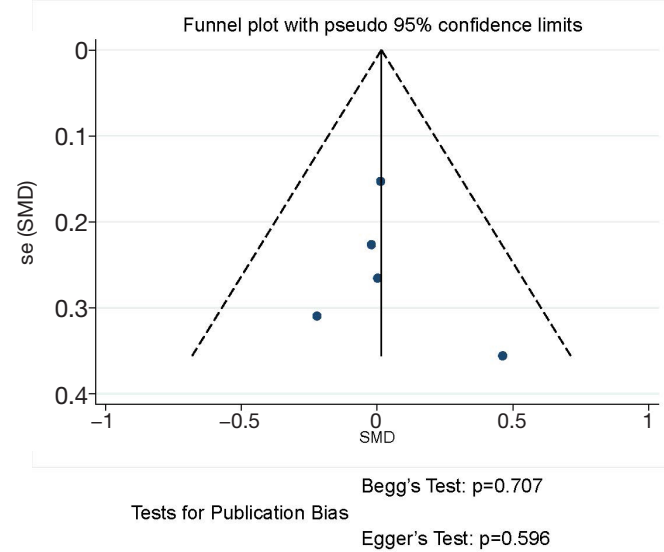

Figure S3 The funnel plot and publication bias tests for number of resected lymph nodes of thoracoscopic and thoracotomy sleeve lobectomy. Note: for propensity matched studies, only cases after matching were included.

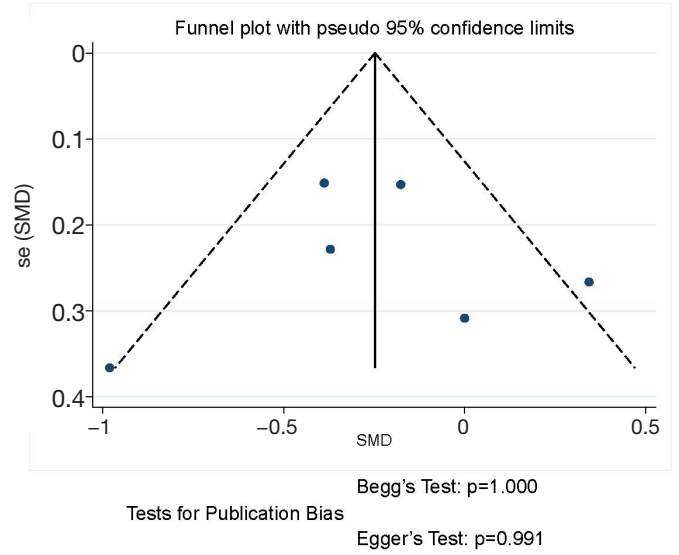

Figure S4 The funnel plot and publication bias tests for postoperative hospital stays of thoracoscopic and thoracotomy sleeve lobectomy. Note: for propensity matched studies, only cases after matching were included. 


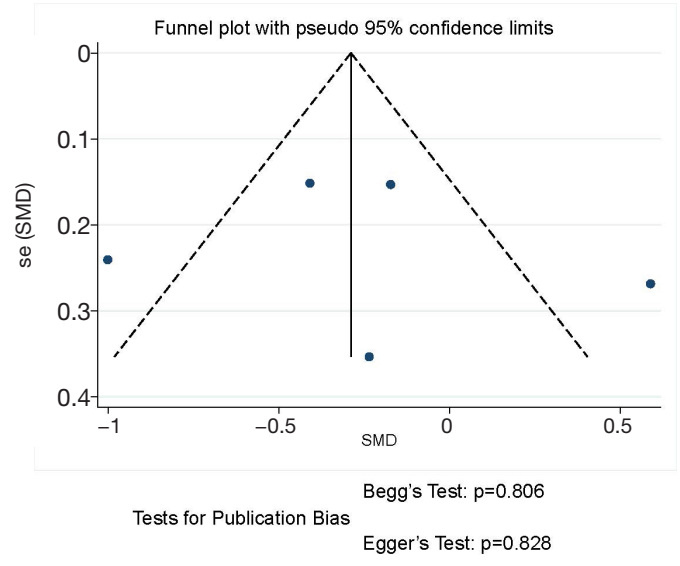

Figure S5 The funnel plot and publication bias tests for chest drainage time of thoracoscopic and thoracotomy sleeve lobectomy. Note: for propensity matched studies, only cases after matching were included.

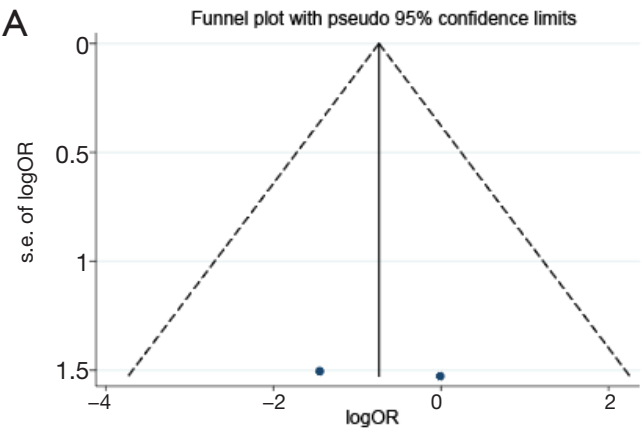

Tests for Publication Bias Begg's Test. $p=1.00$

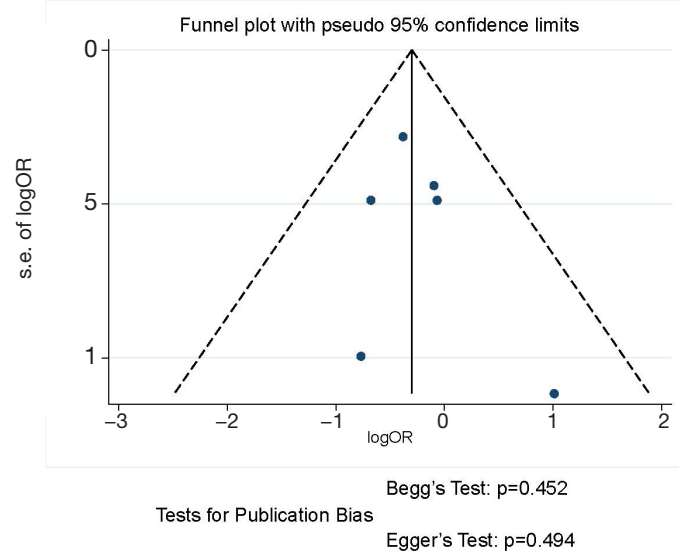

Figure S6 The funnel plot and publication bias tests for postoperative complication rate of thoracoscopic and thoracotomy sleeve lobectomy. Note: for propensity matched studies, only cases after matching were included.

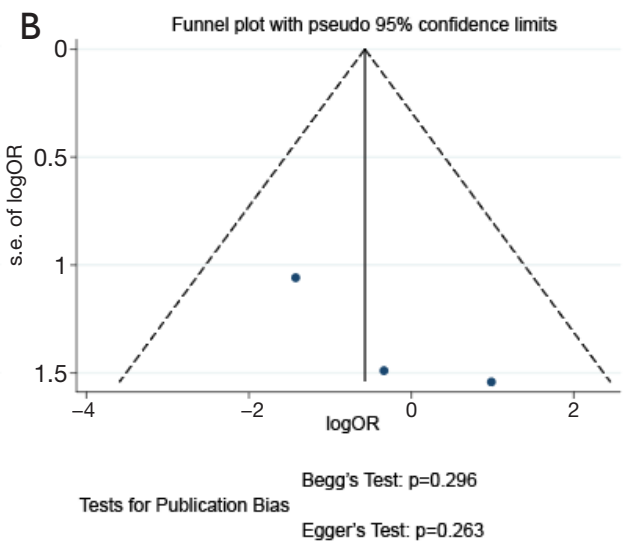

Figure S7 The funnel plot and publication bias tests for 30-day (A) and 90-day (B) mortality of thoracoscopic and thoracotomy sleeve lobectomy. Note: for propensity matched studies, only cases after matching were included. 